\title{
Expanding the definition of noncommunicable disease
}

\author{
Ranabir Salam \\ Department of General Medicine, Regional Institute of Medical Sciences, Imphal, Manipur, India
}

\section{A B S T R A C T}

Noncommunicable diseases (NCDs) are responsible for 68\% of all deaths in 2012. Eighty-two percent of these "premature" deaths occurred in low- and middle-income countries. Most of the NCD deaths are caused by cardiovascular diseases, cancer, diabetes, chronic respiratory diseases, mental health, road traffic accidents, and violence. The World Health Organization, several governments, and nongovernmental organizations have taken up numerous programs to curb the menace of NCDs. However, the present programs do not include some common chronic medical conditions which also lead to considerable morbidity and mortality. The present review highlights three important chronic disorders: chronic kidney disease (CKD), liver disease (cirrhosis and nonalcoholic fatty liver), and thyroid diseases. CKD is an internationally recognized public health problem affecting 5-10\% of the world population. CKD resulted in 956,000 deaths in 2013 and proposes them to be included in the world wide accepted definition of NCD. Cirrhosis and chronic liver disease were the tenth leading cause of death for men and the twelfth for women in the United States in 200I. Moreover, 4-10\% of the global population have thyroid dysfunction. This mini-review proposes to expand the definition of NCD to include these three major illnesses.

Key words: Chronic kidney disease, nonalcoholic fatty liver, noncommunicable disease, thyroid disease

\section{INTRODUCTION}

Noncommunicable diseases (NCDs), also known as chronic diseases, are not transmissible from person to person. They are of long duration and generally progress slowly. ${ }^{[1]}$ They are also referred to as a "lifestyle" disease because the majority of these diseases are preventable illnesses with risk factors include tobacco use (smoking), alcohol abuse, poor diets (high consumption of sugar, salt, saturated fats, and trans fatty acids), and physical inactivity. NCD kills 36 million people a year, a number that by some estimates are expected to rise by $17-24 \%$ within the next decade. ${ }^{[2]}$

All age groups and all regions of the world are affected by NCDs. In 2012, they cause $68 \%$ of all deaths (38 million)

\begin{tabular}{|l|l|}
\hline \multicolumn{2}{|c|}{ Access this article online } \\
\hline Quick Response Code: & Website: \\
\hline & www.joshd.net \\
\hline & \\
\hline & \\
\hline
\end{tabular}

up from $60 \%$ in $2000 .{ }^{[3]}$ About half were under age 70 , and half were women. ${ }^{[4]}$ Eighty-two percent of these "premature" deaths occurred in low- and middle-income countries. ${ }^{[1]}$ Most of the NCD deaths are caused by cardiovascular diseases (CVDs), cancer, diabetes, chronic respiratory diseases (CRDs), mental health, road traffic accidents, and violence. ${ }^{[5]}$

Tobacco accounts for around 6 million deaths every year (including from the effects of exposure to second-hand smoke) and is projected to increase to 8 million by 2030 . About 3.2 million deaths annually can be attributed to insufficient physical activity. ${ }^{[6]}$ More than half of the

\footnotetext{
This is an open access article distributed under the terms of the Creative Commons Attribution-NonCommercial-ShareAlike 3.0 License, which allows others to remix, tweak, and build upon the work non-commercially, as long as the author is credited and the new creations are licensed under the identical terms.
}

For reprints contact: reprints@medknow.com

How to cite this article: Salam R. Expanding the definition of noncommunicable disease. J Soc Health Diabetes 2016;4:67-70.

Corresponding Author: Dr. Ranabir Salam, Department of General Medicine, Regional Institute of Medical Sciences, Imphal, Manipur, India. E-mail: salamranabir@yahoo.co.in 
3.3 million annual deaths from harmful drinking are from NCDs. ${ }^{[1]}$ In 2010, 1.7 million annual deaths from cardiovascular causes have been attributed to excess salt/sodium intake. ${ }^{[7]}$ Elevated blood pressure is attributed to $18 \%$ of global deaths. ${ }^{[6]}$

These diseases are driven by forces that include aging, rapid unplanned urbanization, and the globalization of unhealthy lifestyles. Globalization of unhealthy lifestyles such as unhealthy diets may show up in individuals as raised blood pressure, increased blood glucose, elevated blood lipids, and obesity. ${ }^{[1]}$

In India, according to the recent statistics on NCDs, $53 \%$ of the deaths were due to NCDs. CVDs alone account for $24 \%$ of all deaths. CRDs, cancers, and diabetes accounted for $11 \%, 6 \%$, and $2 \%$ of all deaths, respectively. ${ }^{[8]}$ In 2004 , NCDs accounted for $40 \%$ of all hospital stays and $35 \%$ of all outpatient visits in India. ${ }^{[9]}$ In addition, chronic diseases are estimated to account for $53 \%$ of all deaths and $44 \%$ of disability-adjusted life-years lost in 2005. ${ }^{[10]}$

\section{WHAT ARE THE SOCIOECONOMIC IMPACTS OF NONCOMMUNICABLE DISEASES?}

Previously, chronic NCDs were considered a problem limited mostly to high-income countries while infectious diseases seemed to affect low-income countries. The burden of disease attributed to NCDs has been estimated at $85 \%$ in industrialized nations, $70 \%$ in middle-income nations, and nearly 50\% in countries with the lowest national incomes. ${ }^{[11]}$ There are 7 trillion dollars projected economic losses estimated from NCDs in low- and middle-income countries. ${ }^{[5]}$

Countries are reportedly suffering significant losses in national incomes because of premature deaths or inability to work resulting from heart disease, stroke, and diabetes. For instance, China was expected to lose roughly \$558 billion in national income between 2005 and 2015 due to early deaths. In 2005, heart disease, stroke, and diabetes caused an estimated loss in national income of 9 billion dollars in India and 3 billion dollars in Brazil. ${ }^{[11]}$

As of 2005, India experienced the highest loss in potentially productive years of life worldwide. ${ }^{[12]}$ The projected cumulative loss in Indian national income due to NCD mortality for 2006-2015 is expected to be 237 billion dollars. By 2030, this productivity loss is expected to double to 17.9 million years lost. ${ }^{[13]}$

In collaboration with World Health Organization (WHO), more than 190 countries agreed in 2011 on global mechanisms to reduce the avoidable NCD burden including a Global Action Plan for the prevention and control of NCDs 2013-2020. The aim is to reduce the number of premature deaths from NCDs by $25 \%$ by 2025 through nine voluntary global targets. The focus is in addressing risk factors such as tobacco use, harmful use of alcohol, unhealthy diet, and physical inactivity that increase NCDs. ${ }^{[1]}$

In India to tackle the problem of NCD several programs is being implemented by the Government of India. These include National Program for Prevention and Control of Cancer, Diabetes, Cardiovascular Diseases and Stroke, National Programme of Health Care of Elderly, National Iodine Deficiency Disorders Control Programme, National Programme for Control of Blindness, National Mental Health Programme, and National Programme for Prevention and Control of Deafness. ${ }^{[14]}$

However, there are several common diseases which are not included in the WHO priority list. These diseases can also lead to considerable morbidity and mortality.

\section{ChRONIC KIDNEY DISEASE}

Chronic kidney disease (CKD) is an internationally recognized public health problem affecting $5-10 \%$ of the world population. ${ }^{[15,16]} \mathrm{CKD}$ resulted in 956,000 deaths in 2013 up from 409,000 deaths in 1990. ${ }^{117]}$ In Canada, 1.9-2.3 million people have CKD. ${ }^{[18]}$ The U.S. Centers for Disease Control and Prevention found that CKD affected an estimated $16.8 \%$ of U.S. adults aged 20 years and older, during 1999-2004. ${ }^{[19]}$ UK estimates suggest that $8.8 \%$ of the population of Great Britain and Northern Ireland have symptomatic CKD. ${ }^{[20]} \mathrm{A}$ study from Delhi reported a $0.78 \%$ prevalence of chronic renal failure in adults. ${ }^{[21]}$

Although it is not currently identified as one of the WHO's main target for global NCD control, there is compelling evidence that it is common, harmful but treatable. It is also a major contributor to the incidence and outcome of at least three of the diseases targeted by the WHO that is diabetes, hypertension, and CVD. ${ }^{[22]}$ CKD strongly predisposes to hypertension and CVD.

\section{LIVER DISEASE}

Cirrhosis and chronic liver disease were the tenth leading cause of death for men and the twelfth for women in the United States in 2001, killing about 27,000 people each year. ${ }^{[23]}$ Cirrhosis has a 10 -year mortality of $34-66 \%$, largely dependent on the cause of the cirrhosis; alcoholic cirrhosis has a worse prognosis than primary biliary cirrhosis and cirrhosis due to hepatitis. ${ }^{[24]}$ 
Nonalcoholic fatty liver disease (NAFLD) is the most common liver disorder in developed countries. ${ }^{[25,26]} \mathrm{Up}$ to $80 \%$ of obese people have the disease. ${ }^{[27]}$ The National Health and Nutrition Examination Survey found a 30\% rate of NAFLD in the United States between 2011 and 2012. ${ }^{[28]}$ The percentage of people with NAFLD ranges from $9 \%$ to $36.9 \%$ in different parts of the world. ${ }^{[29-31]}$ Approximately, 20\% of the United States population have nonalcoholic fatty liver, and the number of people affected is increasing. ${ }^{[32]}$

Nonalcoholic steatohepatitis (NASH) is the most extreme form of NAFLD and is regarded as a major cause of cirrhosis of the liver of unknown etiology. ${ }^{[33]} \mathrm{NASH}$ is a progressive disease with up to $20 \%$ of patients with NASH developing cirrhosis of the liver over 10 years, and $10 \%$ will suffer death related to liver disease. ${ }^{[34]}$

The prevalence of the disease is estimated to be around $10-30 \%$ in the general Indian population, with a higher incidence rate among obese and diabetic patients. ${ }^{[35,36]}$ The prevalence is much higher among patients with metabolic syndrome; $15-80 \%$ among obese people, $25-60 \%$ in patients with dyslipidemia, and $33-55 \%$ in prediabetics and diabetics are reported to have NAFLD. ${ }^{[37]}$

\section{THYROID DISEASE}

In a population-based study done in Cochin on 971 adult subjects, the prevalence of hypothyroidism was $3.9 \%$. The prevalence of subclinical hypothyroidism was 9.4\%. Subclinical and overt hyperthyroidism were present in $1.6 \%$ and $1.3 \%$ of subjects studied. ${ }^{[38]}$ In a study of Hashimoto's thyroiditis in India, 6283 schoolgirls from all over the country were screened. Goiter was seen in 1810 schoolgirls and 764 of them underwent a fine needle aspiration cytology, and of these subjects, 58 (7.5\%) had evidence of juvenile autoimmune thyroiditis. Among those with juvenile autoimmune thyroiditis, subclinical and overt hypothyroidism were seen in $15 \%$ and $6.5 \%$, respectively. ${ }^{[39]}$

Patients with diabetes mellitus have higher prevalence of thyroid dysfunction. Diabetes and primary hypothyroidism are common companions as suggested by the $11-20 \%$ concordance of both endocrine disorders in a large cohort study. This is substantially higher than the reported $4 \%$ prevalence of hypothyroidism alone in the general Western population. ${ }^{[40,41]}$ In a study of 202 type 2 diabetes mellitus at Imphal, 16.3\% have subclinical hypothyroidism, 11.4\% have hypothyroidism, $2 \%$ have subclinical hyperthyroidism, and 1.55 are hyperthyroid. ${ }^{[42]}$
The presence of undiagnosed hypothyroidism may increase the risk of CVD by aggravating dyslipidemia, insulin resistance, obesity, and vascular endothelial dysfunction. ${ }^{[43,44]}$

\section{CONCLUSION}

NCD are a common cause of morbidity and mortality across the globe with the major burden on middle- and low-income countries. The WHO and several governmental and nongovernmental organizations have launched several programs to tackle the risk factors for these. However, all these have ignored some very common chronic diseases which also can lead to significant morbidity and/or mortality. So rather than focusing on four main types of NCDs, i.e., CVDs (like heart attacks and stroke), cancers, CRDs (such as chronic obstructed pulmonary disease and asthma), and diabetes; the definition of NCD should also encompass other common chronic noninfectious diseases like thyroid disorders, kidney disease, and chronic liver disease.

Financial support and sponsorship Nil.

\section{Conflicts of interest}

There are no conflicts of interest.

\section{REFERENCES}

1. Noncommunicable Diseases. WHO Fact Sheet: Updated; January, 2015. Available from: http://www.who.int/mediacentre/ factsheets/fs355/en/. [Last accessed on 2016 Jun 27].

2. Non-communicable diseases deemed development challenge of 'Epidemic Proportions' in political declaration adopted during landmark general assembly summit. New York: United Nations, Department of Public Information; 2011. Available from: http:// www.un.org/en/ga/ncdmeeting2011/.

3. The Top 10 Causes of Death. World Health Organization. Available from: www.who.int/mediacentre/factsheets/fs310/en. [Last accessed on 2016 Jun 27].

4. Noncommunicable Diseases. World Health Organization. Available from: www.who.int/mediacentre/factsheets/fs355/en/. [Last accessed on 2016 Jun 27].

5. Global noncommunicable diseases. Saving lives by reducing risk. Centers for Disease Control and Prevention (CDC); 20 April, 2016. Available from: www.cdc.gov/globalhealth/healthprotection/ncd/. [Last Accessed on 2016 Jul 02].

6. Lim SS, Vos T, Flaxman AD, Danaei G, Shibuya K, Adair-Rohani H, et al. A comparative risk assessment of burden of disease and injury attributable to 67 risk factors and risk factor clusters in 21 regions, 1990-2010: A systematic analysis for the global burden of disease study 2010. Lancet 2012;380:2224-60.

7. Mozaffarian D, Fahimi S, Singh GM, Micha R, Khatibzadeh S, Engell RE, et al. Global sodium consumption and death from cardiovascular causes. N Engl J Med 2014;371:624-34.

8. World Health Organization. Non-communicable Diseases Country Profile; 2011. Available from: www.who.int/nmh/publications/ 
ncd_profiles2011/en/. [Last accessed on 2016 Jun 27].

9. Mahal A, Karan A, Engelgau M. The economic implications of non-communicable disease for India. Washington, DC: The International Bank for Reconstruction and Development/The World Bank; 2009. p. xiv.

10. ICMR-MRC Workshop. Building Indo-UK Collaboration in Chronic Diseases; 2009. p. 16.

11. Preventing Chronic Diseases a Vital Investment. Geneva: Cataloguing-in-Publication Data (World Health Organization); 2005. p. 1.

12. Srinath Reddy K, Shah B, Varghese C, Ramadoss A. Responding to the threat of chronic diseases in India. Lancet 2005;366:1744-9.

13. World Health Organization. Chronic Disease Report; 2005. Prakash R. Upadhay from AllMS, New Delhi published in Iranian J Publ Health 2012;41:1-8.

14. Prevention and Control of Non Communicable Diseases. Ministry of Health \& Family Welfare-Government of India. Available from: http://www.mohfw.nic.in. [Last accessed on $2016 \mathrm{Jul}$ 02].

15. Eknoyan G, Lameire N, Barsoum R, Eckardt KU, Levin A, Levin N, et al. The burden of kidney disease: Improving global outcomes. Kidney Int 2004;66:1310-4.

16. Martínez-Castelao A, Górriz JL, Segura-de la Morena J, Cebollada J, Escalada J, Esmatjes E, et al. Consensus document for the detection and management of chronic kidney disease. Nefrologia 2014;34:243-62.

17. GBD Mortality and Causes of Death Collaborators. Global, regional, and national age-sex specific all-cause and cause-specific mortality for 240 causes of death, 1990-2013: A systematic analysis for the global burden of disease study 2013. Lancet 2015;385:117-71.

18. Levin A, Hemmelgarn B, Culleton B, Tobe S, McFarlane P, Ruzicka M, et al. Guidelines for the management of chronic kidney disease. CMAJ 2008;179:1154-62.

19. Centers for Disease Control and Prevention (CDC). Prevalence of chronic kidney disease and associated risk factors - United States, 1999-2004. MMWR Morb Mortal Wkly Rep 2007;56:161-5.

20. Morgan T. Chronic kidney disease (stages 3-5) prevalence estimates using data from the Neoerica study (2007). England: Association of Public Health Observatories; 2009.

21. Agarwal SK, Dash SC, Irshad M, Raju S, Singh R, Pandey RM. Prevalence of chronic renal failure in adults in Delhi, India. Nephrol Dial Transplant 2005;20:1638-42.

22. Zhang QL, Rothenbacher D. Prevalence of chronic kidney disease in population-based studies: Systematic review. BMC Public Health 2008;8:117.

23. Anderson RN, Smith BL. Deaths: Leading causes for 2001. Natl Vital Stat Rep 2003;52:1-85.

24. Sørensen HT, Thulstrup AM, Mellemkjar L, Jepsen P, Christensen E, Olsen $\mathrm{JH}$, et al. Long-term survival and cause-specific mortality in patients with cirrhosis of the liver: A nationwide cohort study in Denmark. J Clin Epidemiol 2003;56:88-93.

25. Shaker M, Tabbaa A, Albeldawi M, Alkhouri N. Liver transplantation for nonalcoholic fatty liver disease: New challenges and new opportunities. World J Gastroenterol 2014;20:5320-30.

26. Rinella ME. Nonalcoholic fatty liver disease: A systematic review. JAMA 2015;313:2263-73.

27. Sanyal AJ. AGA technical review on nonalcoholic fatty liver disease. Bethesda, MD: American Gastroenterological Association; 2002.
28. Ruhl CE, Everhart JE. Fatty liver indices in the multiethnic United States National Health and Nutrition Examination Survey. Aliment Pharmacol Ther 2015;41:65-76.

29. Omagari K, Kadokawa Y, Masuda J, Egawa I, Sawa T, Hazama H, et al. Fatty liver in non-alcoholic non-overweight Japanese adults: Incidence and clinical characteristics. J Gastroenterol Hepatol 2002;17:1098-105.

30. Hilden M, Christoffersen P, Juhl E, Dalgaard JB. Liver histology in a 'normal' population - Examinations of 503 consecutive fatal traffic casualties. Scand J Gastroenterol 1977;12:593-7.

31. Shen L, Fan JG, Shao Y, Zeng MD, Wang JR, Luo GH, et al. Prevalence of nonalcoholic fatty liver among administrative officers in Shanghai: An epidemiological survey. World J Gastroenterol 2003;9:1106-10.

32. Lazo M, Hernaez R, Bonekamp S, Kamel IR, Brancati FL, Guallar E, et al. Non-alcoholic fatty liver disease and mortality among US adults: Prospective cohort study. BMJ 2011;343:d6891.

33. Clark JM, Diehl AM. Nonalcoholic fatty liver disease: An underrecognized cause of cryptogenic cirrhosis. JAMA 2003;289:3000-4.

34. McCullough AJ. The clinical features, diagnosis and natural history of nonalcoholic fatty liver disease. Clin Liver Dis 2004;8:521-33, viii.

35. Das K, Das K, Mukherjee PS, Ghosh A, Ghosh S, Mridha AR, et al. Nonobese population in a developing country has a high prevalence of nonalcoholic fatty liver and significant liver disease. Hepatology 2010;51:1593-602.

36. Mohan V, Farooq S, Deepa M, Ravikumar R, Pitchumoni CS. Prevalence of non-alcoholic fatty liver disease in urban South Indians in relation to different grades of glucose intolerance and metabolic syndrome. Diabetes Res Clin Pract 2009;84:84-91.

37. Ingle M, Abraham P. Epidemiology of non-alcoholic fatty liver disease in Asia. Non-alcoholic fatty liver disease: A clinical spectrum. In: Choudhuri G, editor. ECAB Clinical Update: Gastroenterology/Hepatology. New Delhi: Elsevier; 2013. p. 18-28.

38. Usha Menon V, Sundaram KR, Unnikrishnan AG, Jayakumar RV, Nair V, Kumar H. High prevalence of undetected thyroid disorders in an iodine sufficient adult South Indian population. J Indian Med Assoc 2009;107:72-7.

39. Marwaha RK, Tandon N, Karak AK, Gupta N, Verma K, Kochupillai N. Hashimoto's thyroiditis: Countrywide screening of goitrous healthy young girls in postiodization phase in India. $\mathrm{J}$ Clin Endocrinol Metab 2000;85:3798-802.

40. Hollowell JH, Staehling NW, Flanders WD, Hannon WH, Gunter EW, Spencer CA, et al. Serum TSH, T4, and thyroid antibodies in the United States population (1988 to 1994): National Health and Nutrition Examination Survey (NHANES III). J Clin Endocrinol Metab 2002;87:489-99.

41. Olsen AH, Kelsberg G, Coffey J, Hsu JT. Clinical inquiries. Should we screen women for hypothyroidism? J Fam Pract 2004;53:653-5.

42. Demitrost L, Ranabir S. Thyroid dysfunction in type 2 diabetes mellitus: A retrospective study. Indian $\mathrm{J}$ Endocrinol Metab 2012;16 Suppl 2:S334-5.

43. Brenta G. Diabetes and thyroid disorders. Br J Diabetes Vasc Dis 2010;10:172-7.

44. Duntas LH, Orgiazzi J, Brabant G. The interface between thyroid and diabetes mellitus. Clin Endocrinol (Oxf) 2011;75:1-9. 